\title{
JONÁS O LA CONVERSIÓN EN ALTA MAR...*
}

La gente de Nínive se levantará en el juicio contra esta generación y la condenará, porque ella se arrepintió por el anuncio de Jonás, y mirad, jalgo mayor que Jonás está aquí! (Mt 12,41; cf. Lc 11,32)'.

El profeta Jonás es recordado en este pasaje particular del evangelio por su acertada predicación en Nínive. El propósito del dicho de Jesús es seguramente polémico. Él afirma que sus contemporáneos serán condenados por los extranjeros -los ninivitas-, porque ellos creyeron y se convirtieron, mientras los contemporáneos de Jesús no creen en su predicación, aunque Él es más grande que Jonás. En este pasaje, los evangelios sugieren implícitamente, que las buenas noticias fueron anunciadas con éxito a las naciones mientras la mayor parte de los contemporáneos, miembros del pueblo judío, rechazaron escuchar al Mesías. Este hecho nos trae al corazón del libro de Jonás el cual, como veremos, contiene muchas variaciones sobre el tema del "arrepentimiento" o de la "conversión."

El libro de Jonás pertenece a la colección de los doce profetas menores, pero es muy diferente de todos los otros libros proféticos. Contiene una breve narración sobre el profeta Jonás y el único "oráculo" pronunciado tiene, en la lengua original, no más de cinco palabras (Jon 3,4). En ninguna parte del texto encontramos algo similar a los oráculos de un Isaías o de un Jeremías, o las visiones de un Ezequiel o de un Zacarías. Jonás es más cercano a historias cortas, tales como los libros de Rut o de Ester, o a los libros deuterocanónicos de Judit y de Tobías. Por lo tanto, estudiaremos el texto de Jonás con las herramientas del análisis narrativo.

* El presente artículo fue presentado como conferencia en la I Semana Bíblica Argentina, que tuvo lugar en Buenos Aires del 26 al 28 de mayo de 2011.

${ }^{1}$ De ordinario, las citas son de la Biblia de Jerusalén (1998) con algunas correcciones leves o modificaciones en ciertos lugares para una representación más fiel del texto original. 


\section{Introducción (Jonás 1,1-2)}

La primera frase del libro contiene, como en un apretado resumen, la historia entera:

La palabra del Señor vino a Jonás, hijo de Amittai, diciendo: «Ve inmediatamente a Nínive, la gran ciudad, y grita contra ella; porque su maldad ha subido hasta mí.» (Jon 1,1-2).

Jonás, hijo de Amittai, es mencionado en 2 Re 14,25, un profeta que predicó bajo el rey Jeroboam II (785-745 a.C., aproximadamente) ${ }^{2}$. Éste fue el reinado más largo del reino de Israel, un reinado que coincidió con un período de prosperidad.

Pero no hay ninguna evidencia para probar que este Jonás, hijo de Amittai, hubiera ido a Nínive. Es probable que el autor del libro de Jonás simplemente eligiera ese nombre e hiciera de Jonás el héroe de una narración. Veremos que la narración misma sugiere que debemos entenderla como ficción. No obstante, vemos también que el escritor quiso arraigar su narración en una tradición bíblica.

La historia pudo ser un trabajo de imaginación, sin embargo, el nombre no lo es. ¿Es esto para hacer la historia más probable y más creíble? ¿O simplemente para desorientar al lector? No lo sabemos. Probablemente, el autor es fiel a un principio de la literatura antigua, es decir: "Nada se crea, nada se pierde, todo se transforma" (Anaxágoras). Él tuvo que encontrar algún punto sólido en la tradición para hacer aceptable su narración.

La primera frase del libro de Jonás es una fórmula bien conocida que introduce los oráculos ${ }^{3}$. Esta es una primera indicación para el lector: estamos en el mundo de los profetas. Jonás recibe un mensaje para llevar a los ninivitas. Este mensaje es breve, pero significa, en el lenguaje jurídico de la época, que el juez del universo tomó nota de los crímenes cometidos por la ciudad de Nínive y está próximo a actuar según esos hechos. Esto significa, en palabras claras, que los crímenes serán castigados.

Nínive, de hecho, no es una ciudad entre otras. Nínive es la peor ciudad que se podría imaginar en aquella época. Era una de las capitales del imperio asirio que puso fin al reino del norte en 722 a.C. (2 Re 17).

2 El nombre de Jonás, en hebreo yônâ, significa "paloma", pero no parece que esta historia juegue con ese nombre.

${ }^{3}$ Ver Gn 15,1.4 (Dios habla a Abraham); 1 Sam 15,10 (Samuel); 2 Sam 7,4 (Natán); Jr 1,4.11.13; 2,1... La fórmula asoma solamente una vez en el libro de Isaías (Is 38,4, en una narración). En Jeremías aparece 23 veces, en Ezequiel 50 veces. No la encontramos en profetas anteriores, pre-exílicos, tales como Amós, Oseas, Miqueas y el primer Isaías. La fórmula es típicamente exílica o post-exílica. 
Los asirios, conducidos por Senaquerib, sitiaron también a Jerusalén en el 701 a.C., y le impusieron un tributo enorme (2 Re 18; Is 38). El libro del profeta Nahúm no es más que un largo oráculo contra Nínive. Para estar seguros de que entendemos lo que significó Nínive para los destinatarios originales del libro de Jonás, permítanme citar algunos versos de Nahúm 3,1-6:

${ }^{1}$ ¡Ay de la ciudad sanguinaria, mentira toda ella, llena de rapiña, de incesante pillaje! ${ }^{2}$ ¡Chasquido de látigos, estrépito de ruedas! ¡Caballos que galopan, carros que saltan, ${ }^{3}$ caballería que avanza, llamear de espadas, centellear de lanzas... multitud de heridos, montones de muertos, cadáveres sin fin, cadáveres en los que se tropieza! 'Es por las muchas prostituciones de la prostituta, bella de gracia y maestra en sortilegios, que vendía a las naciones con sus prostituciones y a los pueblos con sus sortilegios. ${ }^{5} \mathrm{Aqui}$ estoy contra ti -oráculo de Yahveh Sebaot-: voy a alzar tus faldas hasta tu cara, mostraré a las naciones tu desnudez, a los reinos tu vergüenza. ${ }^{6}$ Arrojaré inmundicia sobre ti, te deshonraré y te pondré como espectáculo.

No es difícil percibir en estos versos la aversión y el odio profundos que en promedio los miembros de Israel podrían sentir hacia la ciudad de Nínive. Por esta razón, el mensaje confiado a Jonás debió alegrar a muchos lectores del libro. Por fin el Señor de Israel está a punto de reaccionar contra la violenta y repugnante ciudad. ¡Al citar otra vez a Nahúm, el lector puede clamar con confianza, finalmente:

¡Mira! ¡Sobre las montañas los pies de quien trae buenas noticias, que proclama paz! Celebra tus fiestas, oh Judá, satisface tus votos, porque nunca más te invadirá de nuevo la maldad [ninivitas]; ellos han sido cortados del todo (Nahúm 1,15).

Hay, sin embargo, un último detalle que merece nuestra atención. Nínive es llamada la "gran" ciudad ( $g \bar{a} d \hat{l} l$ en hebreo). Apenas notamos el hecho, pero este adjetivo se utiliza por primera vez en la narración. Y se repetirá doce veces, si no estoy equivocado. ${ }^{4} \mathrm{El}$ hecho es sorprendente porque la lengua hebrea raramente usa adjetivos. En el libro de Jonás, de repente, todo se vuelve "grande": la ciudad de Nínive, la tempestad, el miedo, el pez, la cólera, la alegría... El significado de esta característica aparecerá progresivamente en el curso de lectura.

A este punto, el lector espera que sucedan dos cosas. Primero, esperamos que Jonás vaya a Nínive. En segundo lugar, que Nínive sea destruida.

4 Jonás $1,2.4$ [2x].10.12.16; 2,1.2.3; 4,1.6.11. Esto pudo ser justo una coincidencia, pero puede también ser significativo. El significado exacto es, sin embargo, difícil de determinar. En el libro de Rut, por ejemplo, el verbo "retornar" se utiliza doce veces en Rut 1 y el verbo "espigar" doce veces en Rut 2. Puede ser justo una manera de subrayar una palabra clave en una historia. 
El lector puede pensar que la tarea de Jonás no es muy fácil. Pero de ordinario un profeta tiene la ayuda de Dios y no vacila para realizar tareas difíciles. Es probable que la misión sea complicada y que él tenga que luchar con varios problemas. Pero en la mayoría de los casos, cuando un profeta es llamado, escucha a Dios y va adonde es enviado.

Antes de leer el resto del primer capítulo, digamos una palabra sobre la construcción del libro. Como varios autores lo han notado, hay un estricto paralelismo entre el primer capítulo y el tercero, como hay también un paralelo entre el segundo y el cuarto capítulo. En el primer capítulo y en el tercero, Jonás trata con los paganos, los marineros en el capítulo 1 y los ninivitas en el capítulo 3. En ambos casos, el capítulo describe una conversión (cf. 1,14; 3,5.16). En los capítulos 2 y 4, Jonás está solo con Dios. En ambos casos, él "ora" $(2,1 ; 4,1)$. Otras características se observarán en el curso de nuestra lectura.

\section{Jonás en el barco (Jon 1,3-16)}

Después de leer Jon 1,1-2, la audiencia espera una frase más o menos así: "Jonás se levantó y fue a Nínive..." No obstante, no es este el caso y esta es la primera sorpresa importante en la narración. ${ }^{5}$ En el texto se lee:

Jonás se levantó para huir a Tarsis, lejos de la presencia del Señor. Bajó a Jope y encontró una nave para ir a Tarsis; entonces pagó su precio y se fue a bordo, para ir con ellos a Tarsis, lejos de la presencia del Señor.

Dos veces se dice que Jonás desea huir "de la presencia del Señor", un comportamiento muy extraño para un profeta. Notemos que la oración no dice: "Jonás se levantó y huyó" o que "él pagó su precio y fue a Tarsis." En ambos casos la oración dice cuidadosamente que Jonás se levantó "para huir a Tarsis, lejos de la presencia del Señor" y que él pagó su precio "para ir a Tarsis, lejos de la presencia del Señor". Es su intención. Si tendrá éxito o no, es otro asunto.

Jonás bajó a Jope, significa hacia el oeste, hacia el mar, para ir a Tarsis, que se identifica a menudo con España y representa en la Biblia algo así como "el fin del mundo.” Es, por cierto, la dirección incorrecta porque Nínive -como todos sabemos- está en el oriente... Jonás se asegura de ir lo

\footnotetext{
${ }^{5}$ Según los especialistas del análisis narrativo, los acontecimientos en una historia pueden ser de dos tipos principalmente. Algunos se esperan, pero el lector no sabe cuándo y cómo ocurrirán; esto se llama "suspenso." O los acontecimientos no se esperan o no corresponden a las expectativas normales y esto se llama "sorpresa." Tenemos seguramente el segundo caso en Jon 1,3.
} 
más lejos posible de Nínive, y del Señor. El texto puede sugerir de esta manera que hay un vínculo implícito entre "la presencia del Señor" -literalmente, "el rostro del Señor"- y "Nínive."

Una última pregunta: ¿por qué Jonás huye del Señor? Nada se dice en esta etapa. El lector puede preguntarse por qué el profeta actúa de una manera tan curiosa e inesperada. Cada lector, en este punto, formula una hipótesis. Quizás Jonás esté asustado porque puede morir en Nínive. O el viaje es demasiado largo, la tarea demasiado difícil, el mensaje demasiado duro... De todas formas, la narración abre un boquete que el lector intenta llenar. Más tarde, el lector podrá comprobar si su hipótesis hace agua o no. Tenemos así una narración que involucra al lector desde el comienzo en el proceso de interpretación.

¿Jonás alcanzó Tarsis? No. ¿Por qué? Porque tenemos una segunda sorpresa en el v. 5:

... pero el Señor lanzó un gran viento sobre el mar, y también una gran tormenta vino sobre el mar, tanto que la nave amenazaba con romperse.

Esta es una sorpresa, aunque el lector pudo haber pensado que Dios no dejaría a su profeta ir en paz hasta Tarsis sin intervenir. De todas formas, vemos cómo un gran viento provoca una gran tormenta. La nave amenaza con romperse y hundirse.

A este punto, los personajes de la narración reaccionan de dos maneras diversas. La reacción de los marineros es normal y no sorprende a nadie:

Entonces los marineros estaban asustados, y cada uno gritó a su Dios. Ellos lanzaron la carga que estaba en la nave al mar, para aligerarlo para ellos (Jon 1,5a).

Su reacción es religiosa y humana. Primero ellos oran. Aquí descubrimos que son paganos, puesto que ruegan "cada uno a su Dios". Luego, intentan salvar la nave tirando la carga al mar. Intentan simplemente salvar sus vidas. Jonás, sin embargo, tiene una reacción muy diversa que asombra de nuevo al lector:

Jonás, mientras tanto, había bajado al fondo de la nave y se había acostado abajo, y estaba profundamente dormido. (1,5b).

La frase crea un agudo contraste entre la actividad frenética de los marineros y la inmovilidad de Jonás. Podemos notar también que Jonás bajó a Jope $(1,2)$ y ahora baja a la bodega de la nave. Jonás baja; cada vez baja más. Un psicólogo diría que experimenta una depresión profunda.

¿Por qué duerme Jonás? De nuevo, los lectores conjeturan y hacen algunas suposiciones. El narrador no dice una palabra sobre sus posibles razones. ¿Desea tener paz? ¿Desea olvidarse de su misión y todo lo demás? 
¿Está cansado? ¿Está deprimido? Como todos saben, el sueño profundo está conectado a menudo con el agotamiento y la depresión. Y es también una imagen de la muerte, como en el caso de Elías (1 Re 19,4-9). Pero el pobre Jonás no puede dormir lo que desea. Esta vez

el capitán vino y le dijo: “¿Qué haces profundamente dormido? ¡Levántate, clama a tu Dios! Quizás [este] Dios nos salve de modo que no perezcamos" $(1,6)$.

El estilo hebreo usa características simples para enviar mensajes al lector. En este caso, la repetición de algunas palabras o de algunas frases. En esta frase, por lo menos dos elementos son de una cierta importancia. Primero, el capitán utiliza el mismo lenguaje de Dios cuando él dice, "levántate...”. El capitán, como Dios, intenta poner a Jonás en movimiento. ¿Pero tiene el capitán más éxito que Dios? ¿Cuál es la motivación del capitán? Éste es el segundo elemento que funciona como una pista en la narración. Por primera vez, un personaje expresa el deseo de "no perecer". Esto volverá en 3,9, en la boca del rey de Nínive, con una fórmula muy similar. El mismo verbo "perecer" reaparecerá otra vez en Jon 1,14 y 4,10.

El capitán -volviendo a nuestro asunto- no quiere que su tripulación perezca. ¿Y Jonás? La imagen de Jonás, yacente en el piso de la nave y dormido durante la tormenta, no es exactamente la imagen de alguien que lucha por sobrevivir, ni por él ni por la tripulación.

La escena corta en seco sin darnos la respuesta de Jonás. Nunca sabremos si él oró o no. ¿Lo que importaba al narrador era mostrar la impaciencia del capitán en contraste con Jonás? ¿Es un descuido de Jonás o, más sencillamente, quizás, indiferencia? Vemos a Jonás e intentamos conjeturar cuáles son sus motivaciones. Y, como algo casi inevitable, nosotros juzgamos a Jonás.

La siguiente escena breve comienza sin transición. En verdad, toda la historia de Jonás está hecha de una serie de cuadros cortos. En esta escena (1,7-9), Jonás está despierto y tiene que hacer frente a un tipo de prueba. Los marineros comienzan una investigación para descubrir la causa de su adversidad:

${ }^{7}$ Los marineros se dijeron unos a otros: "Venid, echemos suertes, así sabremos por culpa de quién ha venido esta calamidad sobre nosotros." Echaron suertes, y la suerte cayó sobre Jonás. ${ }^{8}$ Entonces le dijeron: “Dinos por qué esta calamidad ha venido sobre nosotros. ¿Cuál es tu ocupación? ¿De dónde vienes? ¿Cuál es tu país? ¿Y de qué pueblo eres tú?" 9 “Soy un hebreo," contestó él. "Yo temo al Señor, Dios del cielo, que hizo el mar y la tierra seca".

Jonás, quien intentó "huir de la presencia del Señor" $(1,3)$, es molestado otra vez. Después del capitán, los marineros vienen ahora a perturbar la "paz" de Jonás. Ellos echaron suertes, como era usual en aquella 
época ${ }^{6}$. Un paralelo muy cercano se encuentra en Jos 7,16-18. La creencia normal es que todo fenómeno, especialmente una catástrofe, debe tener una causa, y que la causa es, de ordinario, la presencia de una persona culpable ${ }^{7}$. La persona culpable, como el lector pensó, no puede ser sino Jonás. Él es entonces interrogado por los marineros sobre su identidad y su profesión. Pero su única respuesta es una especie de confesión de fe: "Yo soy hebreo. Al Señor, Dios del cielo yo temo, quien hizo el mar y la tierra seca" (traducción literal). Es imposible no percibir una clara nota de chauvinismo en esta afirmación. Jonás quiere decir, "Yo soy hebreo y ustedes son paganos. Yo temo al Señor, el único Dios verdadero, quién creó el cielo, la tierra y el mar. Ustedes adoran falsos dioses".

Hay una cierta ironía en esta confesión de fe. Jonás dice que él "teme" al Señor. Esto puede significar, como reflejan algunas traducciones: "Yo adoro al Señor". Sin embargo, el mismo verbo hebreo significa también: "Yo soy temeroso del Señor". Jonás piensa seguramente el verbo en el primer significado, pero el lector puede preferir el segundo ${ }^{8}$. De hecho, Jonás menciona al Señor, pero no la misión que el Señor le confió. Y, esto es también irónico. Él confiesa que su Dios es el Señor del cielo quien hizo el mar y la tierra seca. ¿Por qué Jonás intenta entonces huir por el mar? ¿No puede su Dios encontrarlo incluso en el profundo mar? Esta es, otra vez, una pregunta que solamente se hacen los lectores. Seguramente, Jonás no está enterado de esta implicación de su (ijactancioso?) acto de fe. Y Jonás puede confesar a su Señor. Jonás no le dirige una oración. Él habla del Señor, no al Señor.

En el v. 10 encontramos una breve retrospectiva:

Entonces los hombres estaban asustados con un gran miedo y le dijeron: “¡Qué has hecho!” Porque los hombres sabían que él huía de la presencia del Señor, porque él les había contado.

La construcción de esta parte de la narración puede alamar al lector. ¿Cuándo les dijo Jonás a los marineros que él huía lejos del Señor? No lo sabemos. El hecho es que el lector percibe primero "el gran miedo" de los marineros y solo después conoce cuál es la razón de este miedo. El narrador crea, de esta manera, un contraste obvio entre el "temor del Señor" de Jonás en el v. 9 y el "gran temor" de los marineros en el v. 10. ¿Qué miedo es más auténtico? El lector debe decidir, aquí como en muchos otros casos.

${ }^{6}$ Ver. Lv 16,8; Jos 7,16-18; 1 Sam 10,20; 1 Cr 24,31; 25,8; 26,13-14; Ne 11,1.

${ }^{7}$ Ver, por ejemplo, aparte de Jos 7,16-18, 1 Sam 14,36-45.

${ }^{8}$ Este es un caso típico de la "ironía verbal" pues las mismas palabras tienen un significado diferente para el (los) personajels) en la historia y para el lector. 
Después de la breve prueba, se debe tomar una decisión. Jonás, de hecho, permanece silencioso. Los marineros toman la iniciativa y piden que el culpable les diga qué hacer... una práctica más bien inusual. Esta estrategia, sin embargo, le permite al narrador descubrir otro lado del personaje de Jonás y crear otro contraste (1,11-12):

${ }^{11}$ Y le preguntaron: “¿Qué hemos de hacer contigo para que el mar se nos calme?" Pues el mar seguía encrespándose. ${ }^{12}$ Les respondió: “Agarradme y tiradme al mar, y el mar se os calmará, pues sé que es por mi culpa por lo que os ha sobrevenido esta gran borrasca".

Jonás elige su pena y finalmente reconoce su culpabilidad. Pero su elección revela, de nuevo, que Jonás desea ir abajo, y esta vez al fondo del mar. Ésta no es sino la denominada "muerte-deseada (tendencia al suicidio)". Jonás no quiere vivir. ¿Arrojaron los marineros a Jonás en el mar, como antes lanzaron la carga del barco $(1,5)$ ? No; al menos, no inmediatamente:

Sin embargo, los hombres remaron con dificultad para llevar la nave de nuevo a tierra, pero no podían, porque el mar crecía, cada vez más tempestuoso contra ellos. $(1,13)$

Los marineros intentan por todos los medios salvar a Jonás. El lector casi se vuelve impaciente por ver a Jonás arrojado en el mar. Pero Jonás todavía está en la nave. Y antes de que se cumpla su deseo, los marineros todavía se toman su tiempo para orar:

Entonces ellos gritaron al Señor: "Por favor, oh Señor, nosotros te rogamos, no nos dejes perecer por causa de la vida de este hombre. No nos hagas culpables de sangre inocente; por ti, oh Señor, haremos como tú quieres" $(1,14)$.

Los marineros repiten el famoso verbo "perecer" -"no nos dejes perecer"- mientras Jonás quiere desaparecer en el mar. En segundo lugar, ellos oran al Señor, Dios de Jonás, e implícitamente reconocen que él es el Dios que tiene su destino en sus manos. Esto se puede considerar como mero oportunismo. En la narración parece servir a un propósito diferente -pienso yo- a saber, resaltar el contraste entre su actitud y la de Jonás.

Después de esta oración, los marineros se ven forzados a hacer lo que les había propuesto Jonás a ellos. El efecto previsto es inmediato:

Ellos tomaron a Jonás y lo lanzaron al mar; y el mar cesó de rabiar. $(1,15)$

Quisiéramos conocer la suerte de Jonás, pero el narrador prefiere describir primero la reacción de los marineros después de que la tormenta terminó y ellos se sienten a salvo:

Entonces los hombres temieron al Señor con un gran temor, y ofrecieron un sacrificio al Señor e hicieron votos $(1,16)$. 
El narrador subraya de nuevo la piedad de los marineros: ellos están escandalizados por la desobediencia de Jonás (v. 10), dudan antes de lanzar a Jonás al agua (v. 13), piden el perdón de Dios (v. 14), le ofrecen sacrificios y le hacen votos (v. 16). Después de la confesión de Jonás, ellos se olvidan de sus dioses paganos y mencionan solamente al Señor, Dios de Jonás (Yhwh; cf. 1,10.14.16). La pregunta para el lector es otra vez: ¿quién "teme" realmente al Señor?"

\section{Jonás en el vientre del pez $(2,1-11)$}

Este capítulo contiene una breve noticia sobre la suerte de Jonás (2,1-2.11) y un salmo que Jonás recita en el vientre del pez (2,3-10).

En este capítulo, la narración introduce otro elemento extraordinario, un gran pez que se tragó a Jonás. Él permanece allí tres días y tres noches. Por supuesto, esto no puede tomarse literalmente y el narrador claramente quiere que los lectores entiendan que la narración es ficticia. Estamos en el mundo de la fantasía.

En cuanto al pobre Jonás, no tiene paz. Él seguramente quiso poner fin a todos sus apuros, pero Dios, el Señor, decidió de otra manera. De todas formas, tiene tres días para reflexionar ${ }^{10}$. "Tres días" es una expresión usada de vez en cuando en la Biblia para hablar de un tiempo después del cual uno abandona cualquier esperanza de encontrar a una persona perdi$\mathrm{da}^{11}$. Después de tres días, sin embargo, el pez, literalmente, "vomita" a Jonás en la orilla.

El salmo que encontramos en Jon 2,3-10 plantea varias preguntas. Es muy probable que sea una adición posterior que busca hacer a Jonás un poco más piadoso y tolerable. En este salmo, por ejemplo, no hay mención del pez. Jonás parece estar en el fondo del mar $(2,6-7)$ o en el vientre del Sheol $(2,3)$ y no en el vientre de un pez. No hay tampoco mención de su misión. Finalmente, la acción de gracias quedaría mejor después del v. 11, y no antes. En cuanto al estilo, el canto es un mosaico de distintas oraciones y de versos tomados de los salmos. Las notas marginales en las versiones modernas de la Biblia mencionan la mayor parte de estos paralelos.

\footnotetext{
9 Ver el uso del verbo "temer" en 1,9.10.14, y especialmente la mención del "gran miedo" de los marineros en 1,10.14. El adjetivo "grande" es utilizado para el temor de los marineros, ¿pero se utiliza para el miedo de Jonás?

${ }^{10}$ Este motivo fue tomado por el Nuevo Testamento para subrayar el paralelismo entre Jonás y Jesús, en particular con respecto a los tres días entre la muerte y la resurrección de Jesús. Ver Mt 11,40; Lc 12,30.

${ }^{11}$ Ver 1 Sam 9,20; 1 Re 2,17.
} 
¿Cómo explicar la presencia de un Salmo en el libro de Jonás? Las narraciones populares -y la mayoría de las narraciones bíblicas son narraciones populares- raramente desarrollan los procesos mentales de sus personajes. El interés por la psicología es, por otra parte, una invención moderna. Cuando una narración bíblica quiere describir sensaciones o emociones fuertes, normalmente recurre al lenguaje lírico. Los cantos y los salmos a menudo están presentes para expresar momentos de intensa alegría, dolor, o desesperación. El libro de Job sería el mejor ejemplo de esto. En ese libro hay poca acción y mucha pasión, como Luis Alonso Schökel acostumbraba decir. Hay muchos otros ejemplos. Permítanme mencionar por lo menos algunos de ellos: el "canto" del primer hombre después de la creación de la primera mujer (Gn 2,23); el canto vengativo de Lamec (Gn 4,23-24); el canto de victoria de Débora (Jue 5); el canto alegre de Ana después del nacimiento de Samuel (1 Sam 2,1-10); el canto de victoria de las mujeres después de la muerte de Goliat (1 Sam 18,7); el canto fúnebre de David por Saúl y Jonatán (2 Sam 1,17-27); el canto fúnebre del mismo David por Abner (2 Sam 4,33-34)...

La oración de Jonás expresa sus sensaciones internas, como lo hacen otros cantos. Pero puede ser leído desde diferentes claves de lectura. Yo propongo leerlo de una manera irónica. Permítanme establecer claramente algunos de los casos más visibles donde el lector puede leer el texto con ironía. Dijo:

Desde mi angustia clamé a Yahveh y él me respondió; desde el seno del sheol grité, y tú oíste mi voz $(2,3)$.

Pero, ¿quién oró en 1,5.14?

Me habías arrojado en lo más hondo, en el corazón del mar, una corriente me cercaba: todas tus olas y tus crestas pasaban sobre mí $(2,4)$.

¿Quién pidió ser lanzado en el mar en 1,12?

Yo dije: ¡Arrojado estoy de delante de tus ojos! ¿Cómo volveré a contemplar tu santo Templo? $(2,5)$.

¿Quién huyó de la presencia del Señor $(1,3.10)$ ?

Me envolvían las aguas hasta la garganta, me cercaba el abismo, un alga se enredaba a mi cabeza. A las raíces de los montes descendí, a un país que echó sus cerrojos tras de mí para siempre, mas de la fosa tú sacaste mi vida, Yahveh, Dios mío (2,6-7).

¿Por qué Jonás está en el mar?

Cuando mi alma en mí desfallecía me acordé de Yahveh, y mi oración llegó hasta ti, hasta tu santo Templo $(2,8)$. 
¿Quién recordó al Señor? ¿Y quién oró?

Los que veneran vanos ídolos su propia gracia abandonan $(2,9)$.

¿Quién fue realmente leal al Señor? ¿El hebreo Jonás o los marineros paganos?

Mas yo con voz de acción de gracias te ofreceré sacrificios, los votos que hice cumpliré. ¡De Yahveh la salvación! $(2,10)$.

¿Quién acaba de ofrecer sacrificios al Señor y de hacer votos $(1,16)$ ?

Jonás parece no estar enterado de todas estas contradicciones, de todas formas; y esto suma a la dramática ironía de la historia. En 2,11 Jonás, como vimos, fue vomitado o arrojado sobre la tierra seca. Para los rabinos, Jonás era una persona tan repugnante que incluso el pez no pudo digerirlo y tuvo que arrojarlo fuera después de tres días.

\section{Jonás en Nínive (3,1-10)}

No sabemos exactamente dónde aterriza Jonás en 2,11. Lo más probable es que este hecho no importa. En 3,1-2, recibe una segunda orden, similar a la primera en 1,2:

La palabra del Señor vino a Jonás una segunda vez, diciendo: "Levántate, ve a Nínive, esa gran ciudad, y proclama el mensaje que te diré".

Encontramos otra vez a Nínive, la gran ciudad. Pero el mensaje es diferente. Podríamos pensar que Dios es más cauteloso esta vez y quiere que su profeta primero vaya a Nínive. Una vez que esté allí, Dios le dirá lo que debe decir... Pero nunca sabremos si el mensaje entregado por Jonás en 3,4 es el mensaje exacto que se le pidió trasmitir.

Esta vez, Jonás no intenta huir. Él aprendió la lección: “Jonás se levantó y fue a Nínive, según la palabra del Señor” (3,3). El lector ve aquí la frase que él o ella esperaba encontrar en 1,3. La fórmula de ejecución -“según la palabra del Señor”- seguramente puede ser leída con un matiz irónico: "En última instancia, queriendo o no, dispuesto o no, Jonás actuó según la palabra del Señor".

En el v. 3b, el narrador añade una nota breve como comentario sobre la ciudad de Nínive y sus fabulosas dimensiones:

Nínive era una gran ciudad ante Dios, tres días eran necesarios para atravesarla.

La expresión "una gran ciudad ante Dios" puede entenderse como un superlativo, "una ciudad excesivamente grande". Pero también puede interpretarse como una manera de decir que Nínive era preciosa a los ojos 
de Dios. ¡Una caminata de tres días! ¡Podría significar, más o menos, noventa kilómetros! Esto evoca seguramente un tamaño fabuloso ${ }^{12}$. Como el lector debió notar, casi todo es grande en la historia de Jonás. Y algunas veces, excesivamente grande.

El mensaje de Jonás a los ninivitas contiene solamente cinco palabras en el texto original hebreo:

Jonás comenzó a entrar en la ciudad, e hizo un día de camino, gritando: “¡Cuarenta días más, y Nínive será destruida!” $(3,4)$.

"Cuarenta días", como "tres días", son números simbólicos. En la Biblia, cuarenta días o cuarenta años corresponden a un tiempo de transformación. En una versión del diluvio, el último duró cuarenta días y cuarenta noches (Gn 7,4.12.17). Israel permaneció cuarenta años en el desierto y después de cuarenta años, una nueva generación estuvo lista para entrar en la tierra prometida $(\mathrm{Nm} 14,34)^{13}$.

Jonás -volviendo a nuestro asunto- camina solamente un día y dice cinco palabras. No se puede decir que él exagere o que sea súper celoso y fanático. Todos esperamos la reacción de los ninivitas. Nínive, la peor ciudad del mundo entero, recibe un mensaje de condenación. ¿Cuál es el resultado? ¿Y la consecuencia para Jonás?

El resultado es, una vez más, una sorpresa increíble:

Y la gente de Nínive creyó en Dios; proclamaron un ayuno, y todos, grandes y pequeños, se vistieron de sayal $(3,5)$.

Nunca en Israel un profeta tuvo tal avalancha de éxito. Los lectores dirán que esto es imposible o, por lo menos, increíble. En Israel los profetas de ordinario enfrentan la resistencia, la oposición, la persecución y, en el mejor de los casos, la indiferencia. Y tienen que predicar por años. Aquí, en Nínive, la ciudad entera se convierte después de un día de predicación. ¡Y qué ciudad! La peor que podría ser imaginada. Nínive es, en el Antiguo Testamento, lo que es Babilonia en el libro del Apocalipsis. Obviamente, el narrador crea un agudo contraste entre el mínimo esfuerzo de Jonás y el efecto desproporcionado de su predicación. Produce intencionalmente un fuerte contraste entre la efectiva predicación de Jonás en Nínive y la infructuosa predicación de la mayor parte de los profetas en Israel.

\footnotetext{
${ }^{12}$ Hay un detalle curioso sobre Nínive. El signo cuneiforme para la ciudad de Nínive es el signo para el "pez". Jonás estuvo tres días en el vientre del pez y Nínive -"pez"- es una ciudad que requiere tres días de camino para atravesarla.

${ }^{13}$ Ver también Ex 24,18; 34,28; Nm 13,25; 1 Re 19,8; Mt 4,2...
} 
El versículo siguiente es algo difícil de entender, puesto que uno podría pensar que hay una repetición inútil del v. 5 en las medidas ordenadas por el rey de Nínive $(3,6-9)$ :

${ }^{6}$ La palabra llegó hasta el rey de Nínive, que se levantó de su trono, se quitó su manto, se cubrió de sayal y se sentó en la ceniza. ${ }^{7}$ Luego mandó pregonar y decir en Nínive: "Por mandato del rey y de sus grandes, que hombres y bestias, ganado mayor y menor, no prueben bocado ni pasten ni beban agua. ${ }^{8}$ Que se cubran de sayal y clamen a Dios con fuerza; que cada uno se convierta de su mala conducta y de la violencia que hay en sus manos. ${ }^{9}$ ¡Quién sabe! Quizás vuelva Dios y se arrepienta, se vuelva del ardor de su cólera, y no perezcamos".

¿Cómo explicar, por ejemplo, que el rey proclama un ayuno en el v. 7 cuando, en el v. 5, todos los ninivitas ya decidieron ayunar? La explicación es simple. El v. 5 es una especie de "sumario proléptico" de toda la sección narrativa. Este sumario describe en pocas palabras el efecto inmediato de la predicación de Jonás ${ }^{14}$. Luego, el narrador vuelve al acontecimiento y da al lector todos los detalles necesarios sobre él. En pocas palabras, el narrador nos cuenta que los ninivitas se convirtieron de inmediato y comenzaron a ayunar. Entonces él dice: "Y así sucedieron las cosas: las noticias llegaron al rey..."

Concretamente, el rey de Nínive supo de la predicación de Jonás y reaccionó al instante. Él mismo comenzó a realizar ritos de penitencia. Entonces, después de dar ejemplo, ordena un ayuno público. Hay una clara nota de hipérbole en la orden del rey, como en varias partes del libro de Jonás. El lector ya debe estar habituado a este recurso literario. ¿Podemos imaginar una ciudad entera parando todas sus actividades y ayunando, sin comer ni beber, por cerca de cuarenta días y cuarenta noches? ¿Podemos imaginar millares de personas y millares de animales cubiertos de saco y ceniza, gritando a un Dios que ellos apenas si conocen? ¿Y todo esto en Nínive? En esta narración, esto es lo que sucede.

El rey menciona al final la intención de su decisión: “¿Quién sabe? Quizás Dios pueda aplacarse y cambiar su decisión; él puede volverse de su feroz cólera, de modo que no perezcamos" $(3,9)$. El lector debe reconocer

14 El resumen en el v. 5 es abarcativo. Por ejemplo, la expresión “cada uno, grande y pequeño", "desde el mayor hasta el menor", es el así llamado "merismo," una figura de estilo literario que describe una totalidad usando dos términos opuestos. "Cielo y tierra," por ejemplo, significa el universo (Gn 1,1). Para el merismo "grande y pequeño", ver, por ejemplo, $2 \mathrm{Cr} 31,15 ; 34,30$; Est 1,5, 20; Jr 16,6. En Jon 3,5, la expresión significa cada uno: el rey, la corte, y la población entera de la ciudad. 
aquí un motivo ya presente en el discurso del capitán a Jonás en $1,6^{15}$. Los ninivitas no quieren perecer, así como tampoco lo quisieron el capitán y los marineros.

Esto, evidentemente, no fue dicho por Jonás. Él sólo anunció la aniquilación final de Nínive. No había ni siquiera una alusión indirecta a una posible salvación según lo dicho por él en 3,4. Toda la teología del arrepentimiento y de la salvación viene de la voluntad del rey de Nínive. ¿Quién está en lo correcto? ¿Jonás, que anuncia el final de Nínive, o el rey de Nínive, que espera escapar de la terrible suerte y hace todo lo posible para evitarla? El lector está llamado a proponer las posibles respuestas a esta pregunta ${ }^{16}$.

Hay un rasgo final en el discurso del rey que merece la atención. Él

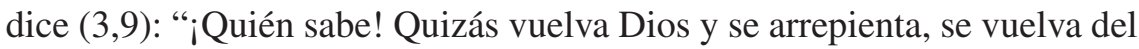
ardor de su cólera, y no perezcamos" (Biblia de Jerusalén). Una traducción más literal sería: "Dios puede volverse atrás y arrepentirse; él puede volverse atrás de su feroz cólera..." Este vocabulario es bien conocido en la Biblia. Es el vocabulario usado para describir una conversión. El narrador sugiere que Dios puede cambiar su mente, que Dios puede "convertirse" y "arrepentirse"... Los marineros lo hicieron, los ninivitas lo hicieron, y después de todo, Dios mismo, puede también convertirse.

¿Cómo reaccionó Dios? El narrador nos da la respuesta enseguida en el v. 10. No describe la ejecución de las órdenes del rey, pues todo estaba ya claro después del v. 5. La reacción de Dios no es exactamente una sorpresa, puesto que a la conversión le sigue normalmente el perdón. Pero esto puede estar acompañado por una cierta decepción desde el lado de los lectores, para quienes es familiar la profecía de Nahúm. El texto lee $(3,10)$ :

Cuando Dios vio lo que ellos hicieron, cómo se volvieron de su conducta malvada, Dios cambió su pensamiento acerca de la calamidad que había dicho que traería sobre ellos; y no lo hizo.

Así pues, finalmente, Dios "se convirtió" también. La narración podría terminar aquí con una especie de "final feliz". Pero algunas preguntas permanecen sin respuesta. Por ejemplo, no conocemos aun la razón por la cual Jonás decidió huir a Tarsis. La respuesta a esta pregunta se da de inmediato en 4,1-4:

\footnotetext{
${ }^{15}$ Ver también la oración de los marineros en 1,14.

${ }^{16}$ Hay en la Biblia un ejemplo de un rey que no se convirtió después de que un profeta, Jeremías, lo invito a hacerlo. Es Yoyaquim, hijo de Josías, en Jr 36 . Puesto que el libro de Jonás es posterior, es posible que el lector informado haya visto en la conducta del rey de Nínive en Jon 3, la conducta opuesta a la de Yoyaquim en Jr 36.
} 
${ }^{1}$ Jonás se disgustó con una gran cólera por esto y se irritó; ${ }^{2}$ y oró al Señor diciendo: “¡Ah, Señor!, ¿no es esto lo que yo decía cuando estaba todavía en mi tierra? Fue por eso por lo que me apresuré a huir a Tarsis. Porque bien sabía yo que tú eres un Dios clemente y misericordioso, tardo a la cólera y rico en amor, que se arrepiente del mal. ${ }^{3}$ Y ahora, Señor, te suplico que me quites la vida, porque me es mejor la muerte que la vida". ${ }^{4}$ Mas el Señor dijo: “ ¿Te parece bien irritarte?"

Ésta es la última reacción en una larga cadena: Jonás es enviado a predicar. Predica. Los ninivitas se convierten. Dios perdona. Jonás muestra su disgusto. Comenzamos con Jonás y volvemos a él en el final.

Jonás está enojado, con una gran cólera $(4,1)$. Y él lo sabía desde el comienzo. La razón por la cual huyó a Tarsis es clara ahora, y el lector es invitado a comprobar si él o ella hicieron la conjetura correcta. Probablemente, no acertaron en la respuesta correcta y tienen que "cambiar sus pensamientos" acerca de las intenciones verdaderas de Jonás. Jonás no puede estar de acuerdo con un Dios de perdón. Esto trastorna todos sus planes. Él queda humillado ante los ninivitas, quienes obtienen el perdón de Dios, mientras que él anunció su caída. Jonás quiere un mundo gobernado por la lógica, no por la misericordia y el perdón. Él anunció la ruina de Nínive y él quiere ver la ruina de Nínive. La maldad de Nínive $(1,2)$ merece el castigo y el castigo debe realizarse. Lógica estricta, justicia estricta, después de todo. Y nada de cambios, por favor. Pero Jonás experimenta que las cosas pueden cambiar (desafortunadamente -podría añadir él-). Incluso Dios puede cambiar su pensamiento. El mundo no está gobernado por la justicia estricta, sino por algo que Jonás llama paciencia, misericordia, amor fiel, y perdón. Ésta es la causa de su depresión y de su famosa muerte-deseada (suicidio) $(4,3)$. Los marineros y el rey de Nínive con los ninivitas no querían perecer $(1,6.14 ; 3,9)$. Jonás, en cambio, quería morir $(4,3)$. Otro contraste que deja al lector ponderando si la imagen verdadera de Dios es la de Jonás o la de los marineros paganos y la de los ninivitas.

La sentencia usada por Jonás para definir el comportamiento de Dios se encuentra también en otros lugares del Antiguo Testamento ${ }^{17}$. El paralelo más cercano, de hecho, se encuentra en Joel 2,13:

Rasguen sus corazones y no sus vestidos. Vuelvan al Señor, su Dios, porque él es compasivo y misericordioso, lento a la cólera, y rico en amor fiel, y se arrepiente del castigo.

${ }^{17}$ Ver, por ejemplo, Ex 34,6 - 7; Nm 14,18; Jl 2,13; Sal 103,8-10. Pero hay muchas otras citas libres de esta fórmula. Las notas marginales en las versiones modernas de la Biblia y de los comentarios dan usualmente una lista de ellas. 
En Joel 2, como también en Jonás 3, tenemos un llamado al arrepentimiento (J1 2,12-17). Y por eso, la frase termina con la misma mención de Dios como "quien se arrepiente del castigo." Para el libro de Jonás, Dios puede perdonar no solo a los israelitas arrepentidos, sino también a los paganos arrepentidos.

Al arrebato de cólera de Jonás, Dios responde con una pregunta sencilla:

Y el Señor le dijo: “ ¿Es correcto para ti estar enojado?” $(4,4)$.

Jonás no contesta a la pregunta. ¿Qué diría el lector? Como veremos, ésta no es la última vez que el texto deja algunas preguntas abiertas.

\section{Dios, Jonás y el lector (Jon 4,5-11)}

La última parte del relato de Jonás genera un cierto problema. Leemos en 4,5 que

Jonás salió de la ciudad y se sentó al oriente de la ciudad, e hizo una choza para él allí. Él se sentó bajo su sombra, esperando ver qué sería de la ciudad.

Esta característica particular de la narración llevó a varios autores a pensar que el texto experimentó un trabajo redaccional. Jon 4,5 debería seguir a Jon 3,4. Jonás predica un día y entonces se retira a una colina y espera allí para ver cuál será la suerte de la ciudad. Ésta es la secuencia lógica y cronológica que el lector puede reconstruir. Pero la narración no presenta los acontecimientos en este orden. La razón para ello es que al narrador le gusta crear efectos especiales.

En nuestro caso, la narración expone el efecto final del perdón de Dios sobre Jonás. Entonces vuelve atrás y explica con más detalles qué sucedió realmente. Obviamente, lo que el lector ya sabe no se repite.

En este caso, el narrador vuelve atrás -esto es lo que se denomina "técnica de tejado (tiling technique)"- y da una segunda versión de la reacción de Jonás con algunos detalles suplementarios. Esta versión contiene la conclusión de la historia. Jon 3,1-4,4 y 4,5-11 deben ser leídos como relatos paralelos del mismo acontecimiento, pero desde diversas perspectivas. En el primer caso, el narrador describe los hechos desde un punto de vista más objetivo y observa especialmente la reacción de los ninivitas. En el segundo caso, Jonás es el centro de atención.

Volvamos, entonces, a nuestra escena. Jonás, después de predicar un día $(3,4)$ sale de la ciudad y va a lo alto de una colina a gozar de una vista agradable con los fuegos artificiales que seguramente acompañarán la con- 
denación de Nínive. Al final, pasados los cuarenta días nada sucede y él comprueba que Dios perdona la ciudad. Por eso, su cólera (4,1-4). Y aquí viene la escena de la planta de ricino (4,6-9):

${ }^{6}$ Entonces el Señor Dios dispuso una planta de ricino que creciese por encima de Jonás para dar sombra a su cabeza y librarle así de su mal. Jonás se regocijó con una gran alegría por aquel ricino. ${ }^{7}$ Pero al día siguiente, al rayar el alba, el Señor mandó a un gusano, y el gusano picó al ricino, que se secó. ${ }^{8} \mathrm{Y}$ al salir el sol, mandó Dios un sofocante viento solano. El sol hirió la cabeza de Jonás, y éste se desvaneció; se deseó la muerte y dijo: “iMejor me es la muerte que la vida!" ${ }^{9}$ Entonces, Dios dijo a Jonás: " ¿Te parece bien irritarte por ese ricino?" Respondió: "¡Sí, me parece bien irritarme hasta la muerte!"

En el v. 6 el narrador utiliza la inusual designación de "Señor Dios", después que utilizó la denominación "Dios," y no "Señor." La razón de esta opción es desconocida y los exegetas realmente no han solucionado este problema. De ordinario, la palabra "Dios" es utilizada solo por los paganos o para los paganos $(1,6 ; 3,4 b .5 .9)$. ¿Es Jonás ahora, de repente, tratado como pagano? Esto, sin embargo, está lejos de ser evidente.

Más interesante es el significado de la escena. Dios le permite a Jonás una experiencia de alegría y de regocijo. En el v. 6 leímos que "Jonás se regocijó con una gran alegría”. ¡Finalmente Jonás es feliz! Ésta es la primera vez en la narración. Y es feliz gracias a una planta... Cuando el ricino muere, cuando Jonás está de pie, un fuerte viento del este ${ }^{18} \mathrm{y}$ el sol golpean su cabeza (que hierve). Jonás quiere morir otra vez, como en 4,3. La pregunta de Dios en 4,9a repite la pregunta de 4,4, la misma cólera de Jonás en 4,9 b es paralela a su cólera en 4,1 . Todas estas indicaciones muestran claramente que estamos otra vez en el mismo punto, pero por una razón diferente. La primera vez que Jonás quiso morir fue porque Nínive no había sido destruida. Esta vez, porque una planta acaba de morir. El paralelismo debe ser claro, quizás no tanto para Jonás, sino para el lector.

Ahora estamos listos para el último golpe:

${ }^{10}$ Y el Señor dijo: "Tú tienes lástima de un ricino por el que nada te fatigaste, que no hiciste tú crecer, que en el término de una noche fue y en el término de una noche feneció. ${ }^{11}$ ¿Y no voy a tener lástima yo de Nínive, la gran ciudad, en la que hay más de ciento veinte mil personas que no distinguen su derecha de su izquierda, y una gran cantidad de animales?" (4,10-11).

La pregunta es clara. Esta vez, el narrador utiliza de nuevo la denominación “el Señor.” Quizás porque él quiere que el Señor, Dios de Israel, sea el único en pronunciar esta última pregunta. El paralelismo es también claro.

${ }^{18} \mathrm{El} \mathrm{famoso}$ hamsin en el Medio Oriente, o scirocco en Italia. En árabe, hamsin significa "cincuenta" porque este viento sopla generalmente por cincuenta horas. 
Jonás tiene compasión de una planta, Dios tiene misericordia de seres humanos (y animales, es decir, de seres vivos). ¿Tiene Dios la razón? ¿Cuál podría ser la respuesta de Jonás? ¿O cuál debería ser la respuesta de Jonás? ¿Y quién debe contestar la pregunta, si la narración no trae una respuesta? Otra pregunta: ¿Quién es Jonás, después de todo? Si alguien contesta la primera pregunta, él o ella es capaz también de contestar la segunda.

\section{Conclusión}

Permítaseme decir una última palabra para redondear estas pocas reflexiones. Nosotros pudimos, muchas veces, haber emitido juicios sobre Jonás. Pudimos haber sentido antipatía, o compasión, y pudimos haber sonreído varias veces. ¿Cuál es nuestra opinión sobre Jonás al final de la historia? Y otra pregunta: ¿Cómo se comporta Dios con Jonás? ¿Por qué es él tan paciente, se retarda a la cólera...? Entonces ¿Cómo debemos tratar a Jonás según la historia misma? Entonces, ¿quién se debe convertir? Vimos que pudimos haber errado cuando conjeturamos la razón por la cual Jonás huyó a Tarsis. Tuvimos que revisar y corregir nuestra opinión en 4,1-4. A lo mejor, tenemos que revisar nuestra opinión también al final de la historia.

\section{Bibliografía selecta}

\section{Historia de la investigación:}

Lichtert, C., "Un siècle de recherche à propos de Jonas", RB 112 (2005) 192-214.

\section{Comentarios:}

Bolin, T.M., Freedom Beyond Forgiveness: The Book of Jonah Re-Examined, JSOTSS 236, Academic Press - Sheffield - 1997).

Golka, F.W., Revelation of God, International Theological Commentary, Grand Rapids, MI / Edinburgh - 1988.

Green, B., Jonah's Journeys, Interfaces, Liturgical Press - Collegeville, MN - 2005.

Magonet, J., Form and Meaning: Studies in Literary Techniques in the Book of Jonah, BET 2, Lang - Bern / Frankfurt - 1976 = Bible and Literature 8, Almond Press - Sheffield, $1983^{2}$.

-, "The Book of Jonah," ABD, III, 936-942.

SAsson, J.M., Jonah: A New Translation with Introduction, Commentary and Interpretation, AB 24b, New York - 1990. 
Wolff, H.W., Obadiah and Jonah: A Commentary, Hermeneia, Fortress Press - Minneapolis, MN - 1986.

\section{Monografías y estudios literarios:}

AcKerman, J.S., "Jonah," The Literary Guide to the Bible (eds. R. Alter F. Kermode), London - 1987.

Antoniotti, G., "La libertà di Dio. La confessione di fede di Gn 4,2 alla luce della sua relazione con Gl 2,13", RivBib 44 (1996) 257-277.

Ben Zvi, E., Sings of Jonah: Reading and Rereading in Ancient Yehud, JSOTS 367, Academic Press - Sheffield - 2003.

Crouch, W.B., "To Question an End, to End a Question: Opening the Closure of the Book of Jonah", JSOT 62 (1994) 101-112.

DAY, J., "Problems in the Interpretation of the Book of Jonah", In Quest of the Past. Studies in Israelite Religion, Literature and Prophetism (ed. A.S. van der Woude), OTS 26, Brill - Leiden - 1990, 32-47.

Good, E.M., Irony in the Old Testament, Fortress Press - Philadelphia, PA - 1985.

Guillaume, P., "The End of Jonah Is the Beginning of Wisdom", Bib 87 (2006) 243-250.

Gunn, D.M. - Fewell, D.N., Narrative in the Hebrew Bible, Oxford University Press - Oxford - 1993, 129-146.

Halpern, B. - Friedman, R.E., "Composition and Paronomasia in the Book of Jonah", HAR 4 (1980) 79-92.

JonKer, L. - LAWrIE, D. (eds.), Fishing for Jonah (Anew): Various Approaches to Biblical Interpretation, Study Guides in Religion and Theology 7, SUN Media - Stellenbosch - 2005.

Lohfink, N., "Jona ging zur Stadt hinaus. Jon 4,4", BZ 5 (1961) 185-203.

McKenzIE, S. L., "The Genre of Jonah," Seeing Signals, Reading Signs: The Art of Exegesis. Studies in Honour of Antony F. Campbell, SJ for his Seventieth Birthday (eds. Mark A. O'Brien - Howard N. Wallace), JSOTS 415, T\&T Clark - London / New York - 2004, 159-171.

PERry, T.A., The Honeymoon Is Over: Jonah's Argument with God, Hendrickson - Peabody, MA - 2006.

JEAN-LOUIS SKA

RoMA

ska@biblico.it 